Results Everyday 150-200 complaints are received and confirmed. Most of the cases are breaking the traffic rules, small cars followed by taxis and buses are the most common vehicles that violate the law. Besides the community share their comments and suggestions. Traffic Police respond immediately to these complaints amid only $28 \%$ can be penalised.

Conclusion Police must have a win/win objectives and mutual benefits from both parties to achieve positive outcomes. This may arise from a genuine interest in road safety, or seeking recognition as a good corporate citizen, social responsibility or for publicity for their own cause.

Even the road rules do not cover all situations, thus rely on community to make good decisions how they use the road safety in general.

\section{ROAD TRAFFIC MORTALITY TRENDS OVER 1971-2014 IN LITHUANIA: IMPACT OF ACTIVITIES AT MACRO LEVEL}

Birute Strukcinskiene. Klaipeda University, LIthuania

10.1136/injuryprev-2016-042156.427

Background The aim of the study was to examine long-term trends in road traffic mortality over 2071 to 2014 in transitional Lithuania, in particular the effect of Independence in 1991.

Methods The data were derived from Statistics and the Archives of Lithuania. Logarithmic regression was used.

Results Road traffic mortality rates showed no significant change over the pre-independence period for the whole group, and in men and women subgroups. However, during the post-independence these rates significantly decreased in the whole population and in both sexes. In addition, a significant decrease in pedestrian mortality was observed. Socioeconomic and political transformations, education, environmentally based measures, legislation, and improved medical care system have contributed to the mortality trends decrease.

Conclusions Traffic deaths fell significantly in Lithuania. Sustainable preventive activities at macro level along with socioeconomic reforms contributed to this result.

\section{ADVOCACY FOR ENHANCED SCHOLAR TRANSPORT POLICIES TO PREVENT CHILD INJURY: A CASE STUDY FROM KENYA}

Gordon Otieno Odundo. Gertrude's Children's Hospital, Nairobi, Kenya

\subsection{6/injuryprev-2016-042156.428}

Background Gertrude's Children's Hospital, Nairobi, Kenya is one of the few hospitals in Sub-Saharan Africa that is dedicated solely to the provision of healthcare for children. In Kenya, where infant and child mortality rates had been decreasing road traffic accidents still constitute to childhood death and injury.

In recognition of the absence of suitable policies and legislation that guide scholar transport Gertrudes Hospital Foundation (GHF) in conjunction with the Global Road Safety Partnership developed an advocacy campaign. The goal of the project was to draw attention to the importance of road safety for children in motor vehicles designated for school transport amongst lawmakers in both the Senate and National Assembly, the National Transport and Safety Authority board members who represent the Kenya Ministry of Transport and senior officials from the Kenya Bureau of Standards and amend the laws.

Methods Our advocacy campaign aimed at bringing the extent of the problem closer and to urge policy makers to prioritise road safety for children. It involved the development of key advocacy resources to use in the campaign, engaging legislators and key policy makers, building effective partnerships and coalitions with existing road safety initiatives for sustainability purposes. The campaign was done through mass media as well as interpersonal channels of communication such as workshops.

Results The Kenyan Parliament has now debated on the new legislation and enacted laws that will ensure that all school transport vehicles are designed and equipped with safety belts, speed calming measures will be placed on major roads passing through school areas, adequate speed limits will be enforced around schools for vehicles and penalties such as fines and jail sentences applied for breaches of the law by motorists.

Conclusions Gertrude's Hospital Foundation has demonstrated that both the public and private sectors can work together to develop policies and legislation that will save the lives of children on their way to school and back.

The key implementation bottlenecks facing the initiative included the long duration it took by the Kenyan parliament to pass the necessary legislation, inadequate knowledge of the impact on children and their families on the lack of policy

\section{PHOTOVOICE: CHILD PARTICIPATION TO DEVELOP SAFER SCHOOL ZONES}

${ }^{1}$ Kronwika Buntanon, ${ }^{1}$ Chatoorong Siribannakoon, ${ }^{1}$ Adisak Plitponkarnpim, ${ }^{2}$ Sitthiphan Phanit-in. ${ }^{1}$ Child Safety Promotion and Injury Prevention Research

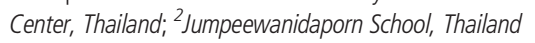

\subsection{6/injuryprev-2016-042156.429}

Background Due to the large concentration of children frequently exposed to vehicles and the risks vehicles pose to children around schools, in 2015, Safe Kids Thailand (SKT) is led by Child Safety Promotion and Injury Prevention Research Centre (CSIP) have carried out the PHOTOVOICE project at Jumpeewanidaporn School in Nan province to focus on pedestrian safety around school. PHOTOVOICE is to encourage student participation, 12 students aged 10-12 years took photos showing pedestrian risks surrounding their school, that had an impact toward child pedestrians. The photos were presented to the public and relevant authorities so that they can be solved and modified to make the school zone safer for child pedestrians.

Methods Educated students about pedestrian safety and how to take a photo for the PHOTOVOICE project. Conducted preand post-assessment. Carried out a map relevant to the safety round. Presented all the photos taken by students in PHOTOVOICE exhibition and established working groups from relevant agencies to collaborate with students to solve the risk.

Results From the pre- and post-assessment, it found that students' knowledge increased from $72 \%$ to $96 \%$. From the 12 photo selection by students, it showed that they had better understanding about pedestrian risks and could select the photos that showed greatest risks for exhibition, for public voting, and for modification. The working group has examined any additional risks and found that there were 13 risk areas to be modified (including the risks from PHOTOVOICE). The sample pedestrian risks are that shops on walkways in front of school caused the students walk on street, no student drop-off area causing the parking get messy, no pedestrian crossing and no traffic light near 
school zone, etc. All the risks have been modified completely with the collaboration from every sector.

Conclusions Child participation in PHOTOVOICE project does not only educate students and change their behaviour about pedestrian safety, it also inspires adults and relevant agencies to modify all the risk environment to make safer pedestrian. This project will serve as an example to other schools, governments and organisations working to improve safety.

\section{Violence Prevention and Child Maltreatment}

\section{Post Mon 1.5}

\section{STRUCTURAL PATHWAYS BETWEEN CHILD ABUSE, POOR MENTAL HEALTH AND MALE PERPETRATED PARTNER VIOLENCE}

${ }^{1}$ Mercilene T Machisa, ${ }^{2}$ Nicola Christofides, ${ }^{1}$ Rachel Jewkes. 'SAMRC and University of Witswatersrand, South Africa; ${ }^{2}$ University of Witswatersrand, South Africa

\subsection{6/injuryprev-2016-042156.430}

Background Violent trauma exposures, including child abuse, increase risk for post-traumatic stress disorder (PTSD), comorbid mental health disorders and exacerbate intimate partner violence (IPV) perpetration. Knowledge about pathways between child abuse, poor mental health and IPV perpetration is emerging. Our study describes the pathways between men's child abuse and IPV perpetration while exploring the mediating effect of poor mental health.

Methods We used data from a two-stage clustered, cross-sectional household survey conducted with 416 adult men in South Africa. We used multinomial regression to identify associated factors and Structural Equation Modelling to test the primary hypothesis that binge drinking PTSD or depressive symptoms mediate the relationship of child abuse and IPV perpetration.

Results Of the men: $88 \%$ were physically abused; $20 \%$ were sexually abused as children; 24\% had PTSD symptoms; $24 \%$ had depressive symptoms; $36 \%$ binge drank; $56 \%$ physically abused and $31 \%$ sexually abused partners in their lifetime. $22 \%$ of men had one episode and $40 \%$ had repeat episodes of IPV perpetration. PTSD risk increased with severity of child trauma or other trauma. PTSD increased the risk for binge drinking. Child or other trauma and PTSD increased the severity of depression. PTSD was comorbid with binge drinking and depression. Neutral and highly equitable gender attitudes were protective against a single episode of IPV perpetration. Child or other trauma, employment in past 12 months and PTSD increased the risk of repeat episodes of IPV perpetration. Highly equitable gender attitudes protected against repeat episodes of IPV perpetration. There was a direct path between the history of child trauma and IPV perpetration and 3 indirect paths showing the mediating effects of PTSD, other trauma and gender attitudes.

Conclusions Child trauma history exacerbates poor mental health and male perpetrated IPV. The observed paths can be explained by a combination of the feminist, social learning and trauma theories. IPV prevention interventions need to address psychosocial support for abused boys and perpetrators.

\section{GENERAL PRACTITIONERS' KNOWLEDGE AND ATTITUDES ON GENDER-BASED VIOLENCE: A CROSS SECTIONAL STUDY IN SRI LANKA}

Achini Jayatilleke, Lakshmen Senanayake, Sumithra Tissera, Dileep Gamage, Tiny T Weerakkodi. Family Planning Association of Sri Lanka, Colombo, Sri Lanka

\subsection{6/injuryprev-2016-042156.431}

Background In Sri Lanka, General Practitioners (GPs) meet survivors of gender-based violence (GBV) on daily basis. However, probably because GPs are not trained on GBV or hold negative GBV related attitudes, they rarely identify and assist survivors in their GP practices. This study aimed to assess Sri Lankan GPs' existing knowledge and attitudes regarding GBV in order to understand how they might affect GPs' GBV services.

Methods We conducted a postal survey with all the registered full-time GPs in Sri Lanka ( $\mathrm{n}=526)$. On $1^{\text {st }}$ June 2015, an anonymous self-administered structured questionnaire was posted to the GPs, with stamped return envelops. GPs were requested to return the completed questionnaires within four weeks. We made two reminder calls after four and six weeks of posting the questionnaires. By $31^{\text {st }}$ July 2015, 124 GPs returned the completed questionnaires. We analysed those data using SPSS version 20 statistical software.

Findings Majority of the GPs was male (70.5\%) and $84.4 \%$ had obtained their MBBS degree at least 15 years before. Of all, $7.3 \%$ of the GPs were survivors, $2.1 \%$ were perpetrators, and $15.6 \%$ were both survivors and perpetrators of GBV. Majority agreed that GBV survivors rarely complain about GBV (95.9\%), and $76.2 \%$ agreed that if asked in a gender sensitive manner, survivors will disclose GBV to GPs. However, $62.6 \%$ believed that because it is a private matter, GPs should not involve assisting survivors, unless they are requested to do so. Only 28.9\% GPs knew that GBV can lead to suicides during pregnancy and only $29.4 \%$ knew that both spontaneous and induced abortions could be associated with GBV. Only $14.8 \%$ knew that domestic violence law covers emotional violence. Of all, $87 \%$ of the GPs believed that women's behaviour provoke GBV, and $74.8 \%$ believed that provocative dress is a reason for rape.

Conclusion Sri Lankan GPs' knowledge and attitudes on GBV is inadequate. Adequate sensitisation on GBV might improve GP's understanding on GBV.

\section{ROLE OF GOVERNMENT OF TANZANIA IN ADDRESSING INTIMATE PARTNER VIOLENCE: A CASE FROM SINGIDA, TANZANIA}

${ }^{1}$ Agnes Kosia, ${ }^{1}$ Gasto Frumence, ${ }^{2}$ Samweli Likindikoki, ${ }^{1}$ Avemaria Semakafu, ${ }^{3}$ Deodatus Kakoko, ${ }^{1}$ Tumaini Nyamhanga. ${ }^{1}$ Department of Development Studies, School of Public Health and Social Sciences, Muhimbili University of Health and Allied Sciences, P.O. Box 65015, Dar Es Salaam, Tanzania; '2Department of Psychology, School of Mental Health, Muhimbili University of Health and Allied Sciences, P.O. Box 65015, Dar Es Salaam, Tanzania; ${ }^{3}$ Department of Behavioural Sciences, School of Public Health and Social Sciences, Muhimbili University of Health and Allied Sciences, P.O. Box 65015, Dar Es Salaam, Tanzania

\subsection{6/injuryprev-2016-042156.432}

Background According to a WHO multi-country study, Tanzania is among the countries with a high prevalence of Intimate Partner Violence (IPV). The Demographic and Health Survey 2010 shows that there are several regions with high levels of IPV within the country, including Singida. There is an ongoing national effort to strengthen the police as well as the legal and health systems from 